\title{
EL LOCUS HOMO = MICROCOSMOS EN LA LITERATURA POLÍTICA: EGIDIO ROMANO Y DANTE ALIGHIERI
}

Francisco Bertelloni*

SÍNTESIS - El artículo procura mostrar, en primer lugar, la tipologia de la utilización de textos filosóficos a partir de la segunda mitad del s. XIII, concentrándose en el uso de un mismo locus con objetivos teóricos diferentes. Luego reconstruye sintéticamente la tradición del microcosmos en la historia del pensamiento clássico. Analiza luego el locus del hombre microcosmos en sus dos dimensiones: como adunatio, porque reune y sintetiza algo de la natureza de toda la realidad material y espiritual, y como horizonte entre ellos. Luego muestra cómo el microcosmos es utilizado con fines radicalmente opuestos por Egidio en el De ecclesiastica potestate cono reunión y síntesis de todo lo real, y por Dante en la Monarchia, como lugar a partir del cual lo real puede ser diferenciado en mundo material y espiritual.

PALABRAS-CLAVE - Egidio Romano. Dante Alighieri. Filosofia Política. Hombre. Microcosmos.
ABSTRACT - The article aims to show, first of all, the typology on the use of philosophical texts since the second half of the XIIth century, concentrating in the use of the same locus with different theoretical objetives. Then it presents the synthetic reconstruction of the microcosm tradition in the history of classical thought. Then it analyses the locus of man - microcosm in its two dimensions: as adunatio for it joins and synthesises some of the nature of the whole material and spiritual reality; and as horizon between them. It then shows how the miscrocosm is used with totally opposite objectives by Aegidius in De ecclesiastica potestate as a gathering and synthesis of all of the real and by Dante in Monarchia as the place from wich the real can be divided into material an spiritual world.

KEY WORDS - Gil of Rome. Dante Alighieri. Political Philosophy. Man. Microcosmos.

\section{Tipología de la utilización política de textos filosóficos a partir de la segunda mitad del siglo XIII}

A partir de la segunda mitad del siglo XIII comienza a verificarse, dentro del panorama intelectual occidental, un notable incremento en la cantidad de tratados de teoría política. No es que hasta ese momento la edad media no hubiera producido ya algunos textos teóricos sobre el problema, sino que recién a partir de esos años tuvo lugar un sensible aumento de textos de ese género. Las causas de ese incremento fueron, en el orden socio-institucional, el apogeo universitario, y en el

* Universoidade Nacional Argentina/ Buenos Aires.

\begin{tabular}{|l|l|l|l|l|l|}
\hline VERITAS & Porto Alegre & v. 44 & n. 3 & Setembro 1999 & p. 789-804 \\
\hline
\end{tabular}


orden de las ideas, la recepción de Aristóteles. El apogeo institucional de la Universidad fue decisivo en la generación de la nueva literatura política, pues casi todos los autores de textos de teoría política, a partir de mediados del siglo XIII, delatan algún tipo de vínculo, directo o indirecto, con el ambiente universitario.' En relación con la recepción de Aristóteles, se trató de una circunstancia histórica que actuó como punto de inflexión en el desarrollo de la historia de la filosofía medieval, pues el momento en que comienza a hacerse notar el incremento de textos teórico-políticos coincide, casi exactamente, con el momento de la recepción completa de los llamados libri morales aristotélicos.

Algunas investigaciones recientes han intentado poner límites a las corrientes historiográficas que atribuyen, a la recepción medieval del aristotelismo moral y político, una influencia decisiva sobre el fenómeno de incremento de la literatura teorico-política. ${ }^{2}$ Con todo, aunque es verdad que la recepción de Aristóteles puede haber sido considerada de modo unilateral y, consecuentemente, su importancia puede haber sido exagerada, considero que sin embargo es posible seguir afirmando que el conocimiento medieval del nuevo discurso aristotélico acerca de la política contenido en la Politica y en la Ética Nicomaquea desempeñó un papel realmente importante en el surgimiento de ese nuevo tipo de literatura. Pues el nuevo naturalismo político aristotélico, a diferencia de otras teorías sobre la naturaleza que hasta ese momento había conocido la edad

Una primera información sobre las relaciones entre el apogeo de la Universidad y sobre las relacio-
nes entre el curiculum universitario y la teoria politica del siglo XIII ofrece Juergen Miethke en Las
ideas politicas de la edad media, Buenos Aires, 1993, p. $67 \mathrm{ss}$. Aunque se trata de investigaciones
mas especializadas tambien pueden consultarse, los trabajos de Miethke, "Kanonistik, Ekklesiologie
und politische Theorie: Die Rolle des Kirchenrechts in der politischen Theorie des Spaetmittelal-
ters", en: Proceedings of the Ninth International Congress of Medieval Canon Law (Monumenta Iu-
ris Canonici, Series C: Subsidia, Vol. 10), Città del Vaticano, 1997, p. 1023/1050) y "Politische Theo-
rie und die Wissenschaften der mittelalterlichen Universitaet im 14. Jahrhundert", en: Revista da
Faculdade de Ciências Sociais e Humanas (As relações de poder no pensamento político da baixa
idade média) Vol. I, 1994, p. 329 ss.

Aunque no es el caso participar aquí de una polémica que está recién en sus comienzos, podemos mencionarlas distintas posiciones acerca del problema. Una de las partes, representada por Walter Ullmann ha presentado la historia del pensamiento político basada en dos hilos conductores: por un lado la descending thesis, predominante hasta el siglo XII, basada en la idea del poder descendente y recibido como gratia Dei, y por el otro la ascending thesis, que habría roto la primera gracias a la recepción de Aristóteles en el siglo XIII. Según Ullmann, el conocimiento medieval de los libros de ética y de política de Aristóteles habria sido decisivo y revolucionario en la constitución de las teorias políticas que llama "ascendentes". Véase W. Ullmann, Principles of Government and Politics in the Middle Ages, Londres, $1978^{4}$ (en la ed. esp., Principios de gobiemo y politica en la edad media, Madrid, 1961, p. 235 ss.) y A History of Political Thought: The Middle Ages, Harmondsworth, $1975^{3}$ (en la ed. esp., Historia del pensamiento político en la edad media, Barcelona, 1983, p. 152 ss.). Frente a lo que llaman una exagerada atribución a Aristóteles de protagonismo en la "revolución" de la teoria política en el siglo XIII - i.e. en la "ruptura de la concepción descendente -, han reaccionado, por una parte, Antony Black, en El pensamiento político en Europa, 1250-1450, Cambridge, 1996, esp. en p. 17 y 30 , y en especial Cary Nederman en "Nature, Sin and the origins of society: The ciceronian tradition in medieval political thought", en Joumal of the History of Ideas, 49 (1988), p. 3-26; id., "Aristotelianism and the origins of 'political science' in the twelfth century", ibid., 52(1991), p. 179-194 y "The meaning of 'Aristotelianism' in medieval moral and political thought", ibid., 57 (1996), p. 563-585. Recientemente Nederman ha publicado un trabajo sobre el problema bajo el título de Medieval Aristotelianism and its limits, Aldershot, UK/Brokkfield, USA, 1997. 
media $^{3}$, se presentaba como un sistema rico en complejidad teónica y completo en sí mismo. En lo que concierne a la teoría política, el nuevo Aristóteles se caracterizaba, sobre todo, por la precisión con que vinculaba estrechamente un discurso sobre la naturaleza que implicaba a todos los ámbitos de lo real y una teoria sobre la naturalidad de los vínculos políticos. Es en especial por ese motivo que el aristotelismo político resultaba atractivo al momento de fundamentar la naturalidad de la política, su especificidad y sus diferencias respecto de las teorías que fundamentaban la politicidad en la historia de la salvación.

Pero independientemente de toda consideración institucional o teóricodoctrinal, es necesario insistir en un hecho histórico incontrastable y decisivo al momento de definir las influencias filosóficas sobre la nueva teoria política: existió una indudable coincidencia cronológica del momento en que comenzó a verificarse el incremento de los tratados de teoria política con el momento en que tuvo lugar el conocimiento de los libri morales de Aristóteles. Este solo hecho debería ser considerado como un motivo más que suficiente, para generar, por lo menos fuertes, sospechas de que, a partir del siglo XIII, pueden haber sido utilizados muchos elementos del aristotelismo moral y político que, por coyunturas históricas, antes no estuvieron a disposición de la teoría política.

En virtud de la gran cantidad de argumentaciones y elementos filosóficos incluídos en la nueva literatura política, cuando ésta apareció logró perfilarse como un género diferente respecto de la literatura precedente. En sus comienzos esa nueva literatura política estuvo caracterizada de modo predominante - aunque ciertamente no de modo exclusivo - por el tratamiento teórico del problema de las relaciones entre los poderes espiritual y temporal. ${ }^{4} \mathrm{Si}$ bien hasta ese momento ese problema había sido tratado en numerosos textos de origen no filosófico, con todo, el problema de las relaciones entre los dos poderes había sido tenido muy poco en cuenta por la literatura propiamente filosófica producida por la edad media occidental hasta el siglo XIII.

Sin embargo, cuando se trata de identificar las influencias filosóficas ejercidas sobre esos textos, constituiría ciertamente un error afirmar que fueron solamente los textos políticos aristotélicos los únicos que brindaron elementos teóricos para la elaboración de la teoría política, pues en cuanto a la reconstrucción de las fuentes y en cuanto a la identificación de los textos utilizados por esa nueva literatura es posible distinguir, por lo menos tres situaciones diferentes entre sí.

La primera de ellas corresponde a la ya mencionada de recepción de textos políticos de Aristóteles. De su análisis resulta con rapidez que si los textos del Aristóteles político habían sido utilizados, es obvio que ello se debió al interés que esos textos despertaban porque se trataba de textos cuya utilidad residia, precisamente, en el hecho de que ellos trataban temas políticos desde una perspectiva estrictamente filosófica.

3 Sobre el naturalismo medieval anterior al siglo XIII véase el trabajo de Tullio Gregory, "L'idea di natura nella filosofia medioevale prima dell'ingresso della fisica di Aristotele", en Atti del III Congresso internazionale di filosofia medioevale, Milano, 1966, p. 27-65.

4 Grabmann ha presentado los primeros efectos del aristotelismo como efectos causados sobre el tema de la relación Iglesia-Estado; cfr. Martin Grabmann, Studien ueber den Einfluss der aristotelischen Philosophie auf die mittelalterlichen Theorien ueber das Verhaeltnis von Kirche und Staat (Sitzungsberichte der Bayerischen Akademie der Wissenschaften, Heft 2), 1934. 
Pero a partir del siglo XIII, la teoría política registra además otro modo de utilización de elementos de la tradición filosófica. Mientras que en el caso de la utilización de los textos políticos de Aristóteles para fundamentar una teoría política, constituiría una afirmación equivocada decir que un texto filosófico estaba siendo politizado - pues esos textos ya constituian de por sí textos políticos - aparece ahora una nueva situación, consistente en la politización de textos filosóficos que originalmente no fueron redactados por sus autores como textos políticos, es decir, de textos que al ser concebidos no fueron pensados para ser integrados dentro de una teoría política. En efecto, a partir de esos años comienza a percibirse que abundantes motivos filosóficos, tanto de origen aristotélico como no anistotélico, que antes nunca habían formado parte de la teoría política, empiezan a ser usados políticamente. A pesar de su intrínseca y originaria apoliticidad, en muchos casos esos motivos fueron utilizados como fundamento teórico en la resolución de momentos decisivos de las argumentaciones de las nuevas doctrinas políticas. Dentro de la generalidad con que he presentado esta situación es posible subdividirla y distinguir en ella, a su vez, dos situaciones que constituyen la segunda y la tercera situación que me interesa diferenciar.

La segunda situación consistió en la utilización política de leitmotivs filosófi$\cos$ no políticos. Al respecto, un trabajo reciente ha analizado la utilización que la teoria política de la baja edad media hizo de aspectos metafísicos del pensamiento de Proclo. Por ejemplo, y para mencionar solamente dos de esos usos, la doctrina de la reductio ad unum de Proclo ha sido - tal como lo muestra el autor del trabajo - uno de los recursos teóricos del que se sirvieron Guillermo de Cremona en su disputa antimarsiliana y Guido Vemani de Rimini en su defensa de la teoría de la plenitudo potestatis papal. ${ }^{5}$

Por último, una tercera situación, que es la situación dentro de la que debe ser encuadrado el tema de este trabajo, está tipificada por la paradójica utilización de un mismo tema filosófico para demostrar tesis políticas radicalmente opuestas. En este caso se verifica la simultánea aparición, en una teoría política, de los mismos - o de similares - motivos filosóficos que aparecen tambien en teorías políticas de signo opuesto. Esta situación se caracteriza por el hecho de que el mismo motivo filosófico es utilizado por teorias opuestas para demostrar, en cada una de ellas, tesis tambien opuestas. Si la reductio ad unum de Proclo, por ejemplo, había sido utilizada por Guillermo de Cremona y por Guido Vernani da Rimini para apoyar la teoría política papal o teocrática, debe recordarse que tambien Dante en cierto modo apeló a ese locus predilecto del neoplatonismo procliano cuando, mediante el recurso al tema de la reductio ad unum implícita en la universalidad de la causa - tomado del Liber de Causis - procuró mostrar la excelencia del gobierno de su monarca único. ${ }^{6}$

5 Cfr. Francis Cheneval, "Proclus politisé. La réception politique de Proclus au moyen âge tardif", en Archiv fuer Geschichte der Philosophie 78 (1996), p. 112/26.

6 "Praeterea, quanto causa est universalior, tanto magis habet rationem causae, quia inferior non est causa nisi per superiorem, ut patet ex hiis que De causis; et quanto causa magis est causa, tanto magis effectum diligit, cum dilectio talis assequator causam per se. Cum igitur Monarcha sit universalissima causa inter mortales ut homines bene vivant, quia principes alii per illum, ut dictum est, consequens est quod bonum hominum ab eo maxime diligatur" (cir. Dante Alighieri, Monarchia, a cura di Pier Giorgio Ricci, Verona, 1965, p. 165-17/166-2). En lo sucesivo cito M, página y líneas de esta edición. 
En el marco de esta tercera utilización de textos filosóficos, cuya tipología queda, pues, perfilada como recurso a los mismos motivos filosóficos, pero con fines políticos opuestos, es mi intención mostrar aquí el uso, en dos teorías políticas radicalmente opuestas, del motivo filosófico del hombre como microcosmos que aparece en la historia de la filosofia fuertemente vinculado tanto con la filosofia de la naturaleza como con el pensamiento antropológico. El tema del microcosmos es utilizado por Egidio en el De ecclesiastica potestate y por Dante en la Monarchia y es interpretado, por cada uno de ellos, procurando potenciar y extrapolar una de las dimensiones del mismo locus que, paradójicamente, es utilizada con fines radicalmente opuestos respecto de la otra.

\section{El locus microcosmos en la tradición filosófica}

La idea del hombre como microcosmos tiene, como referente casi ineludible, la idea del mundo como macrocosmos. Esa suerte de carácter mutuamente referencial del microcosmos respecto del macrocosmos y viceversa está orientado a señalar una fuerte analogía entre ambos, analogía que sugiere que cada uno de ellos se refleja en el otro. Al mismo tiempo, la idea de microcosmos viene acompañada por una serie de conceptos acumulados en él o estrechamente relacionados con él que señalan significados secundarios respecto del significado primario del homo microcosmos. En primer lugar y de modo primordial, el hombre es microcosmos porque es una suerte de adunatio, porque reúne y sintetiza algo de la naturaleza de toda la realidad material y espiritual. En segundo lugar, al mismo tiempo que sintetiza y reúne a ambos mundos, y precisamente porque tiene algo de ambos, es un horizonte entre ellos; en este segundo sentido, el carácter del hombre como síntesis y reunión, que lo convierte en el lugar de la realidad en el que coincide el mundo material y el mundo espiritual, permite transitar al sentido derivado de microcosmos como horizonte, casi como un lugar astronómico o geográfico que simboliza el lugar por donde pasa el límite entre el mundo natural y el mundo espiritual o por donde pasa el límite entre la eternidad y el tiempo. ${ }^{8} \mathrm{Y}$ en tercer lugar, derivado a su vez del segundo sentido, puesto que el hombre es un lugar de confluencia (= microcosmos), pero al mismo tiempo un horizonte entendido como línea de separación entre dos mundos, el hombre es llamado, además de horizonte, tambien medium y confinis.

A partir del significado original de microcosmos como minor mundus y de los sentidos secundarios de horizonte, medium y confinis implicados en esa idea original, la tradición de la idea de microcosmos ha logrado extenderse a través de

La idea de horizonte como categoría espacio-temporal, es decir vinculada a dimensiones geográficas y temporales aparece en Radulphus de Longo Campo, quien lo interpreta en términos astronómicos, según los cuales el cual el horizonte aparece como un límite en el que el cielo toca la tierra: "Horizon enim interpretatur limitans sive finitor visus, ut cum videtur alicui, quod coelum tangat terram. Ad designandum siquidem horizonta inventus fuit in sphaera quidam circulus circumvolvens terram" (cfr. In Anticlaudianus Alani Commentum, de. J. Sulowski, Varsavia, 1972, p. 213).

- El significado temporal de horizonte como límite aparece en Enrique de Gante, quien presenta el aevum como un horizonte o límite entre la eternidad y el tiempo: "Aevum dicitur esse horizon inter aeternitatem et tempus" (cfr. J. P. Zwaenepoel, Les Questions in Librum de Causis attribuées a Henri de Gand, Louvain-Paris, 1974, p. 46 s.). 
numerosíssimas apariciones en la historia de la filosofia, y ello hace casi imposible abarcar aquí todas sus figuras concretas. Con todo, una rápida mención de algunas de sus apariciones históricas y del modo como cada aparición concreta es acompañada por alguno de los tres sentidos señalados, permitirá deslindar las características teóricas de dos sentidos específicos de la idea de microcosmos que son los utilizados políticamente por Egidio y Dante.

Más allá de las atribuciones al microcosmos de significados no antropológi$\cos ,{ }^{9}$ dentro de las doctrinas especificamente antropológicas, la idea del horizonte que se identifica con la de microcosmos asume una función relevante como concepto operativo clave, utilizado para definir el singular y privilegiado lugar del hombre en el universo. Esta idea del horizonte en contexto antropológico tiene dos diferentes ámbitos culturales de aparición: el de la tradición griega y el de la latina.

En la tradición griega ${ }^{10}$ el hombre es microcosmos en el sentido de que es confluencia entre dos mundos y por ello, a su vez, actúa como límite y principio de deslinde entre esos mundos. Es el sentido con que aparece en Filón de Alejandría, para quien el hombre es methónios, es decir limítrofe entre naturaleza mortal e inmortal. ${ }^{11}$ Por su parte, las versiones latinas del De hominis opificio de Gregorio de Nyssa traducidas por Dionisio el Exiguo ${ }^{12}$ y por Juan Escoto Erígena ${ }^{13}$ introducen la idea del homo microcosmos como medium y substantia media respectivamente. Y tambien las versiones latinas del De natura hominis de Nemesio de Émesa traducido primero por Alfano de Salerno ${ }^{14}$ y despues por Burgundio de Pisa ${ }^{15}$

10 Vide supra, notas 7 y 8 .

Para algunas fuentes griegas del horizonte véase N. Hinske, sub voce Horizont, en el Historisches Wörterbuch der Philosophie (hrsg. von J. Ritter), Bd. 3, Wissenschaftliche Buchgesellschaft, Darmstadt, 1974, col. 1187 ss.; v. además M. Kurdzialek, "Der Mensch als Abbild des Kosmos", en Der Begriff repraesentatio im Mittelalter (Miscellanea Mediaevalia 8), Berlin-N.York, 1971, p. 67 ss. Fuentes patrísticas cita G. Verbeke, en "Man as a 'frontier' according to Aquinas", en Aquinas and problems of his time, ed. por G. Verbeke y D. Verhelst (Mediaevalia Lovaniensia, Ser. I,5), Leuven, 1976, p.195 s.

1 Cfr. De opificio mundi, c. 135, en la edición de R. Amaldez, Paris, DU Cerf, 1961, p. 233.

12 "In Christo namque Jesu, sicut dicit Apostolus, neque masculus, neque femina, sed quia per haec divisit hominem sermo divinus, duplex quaedam probatur naturae nostrae formatio, et ea quae ab divinam refert similitudinem, et ea quae $a b$ ista differre monstratur...: duabus rebus secundum summitates $a b$ invicem separatis mediam humanam esse substantiam, inter divinam scilicet incorporeamque et irrationabilem brutamque naturam" (cfr, D. Gregorii Nysseni De Creatione hominis interprete Dionysio Romano Exiguo, en Migne, PL, LXVII, col. 373 C).

13 "In Christo enim Ihess sicut ait apostolus neque masculus neque femina est, sed in haec hominem dividi sermo dicit. Nonne itaque duplex quaedam est nostrae naturae constitutio, unam ad deum assimulata, altera ad talem differentiam divisa...Talis autem doctrina est duorum quorundam per extremitatem a se invicem distantium medium est humanitas divinae videlicet incorporalisque naturae, et irrationabilis pecudalisque vitae" (cfr.M. Cappuyns, "Le 'De imagine' de Grégoire de Nysse traduit par Jean Scot Erigéne", en Recherches de Théologie ancienne et médiévale, 33, 1965, p. $233 \mathrm{~s})$.

${ }^{14}$ "[homo] ideoque tamquam in medio est intellectualis atque sensibilis essentiae, coniunctus quidem per corpus corporalesque virtutes animalibus aliis et inanimatis, per rationabilitatem vero incorporeis substantiis, ut praedictum est" (Nemesii Episcopi Premnon Physicon... a N.Alfano Archiepiscopo Salerni in latinum translatus, ed. C. Burkhard, Leipzig, 1917, p. 7); "in medio irrationabilis rationabilisque naturae homo positus" (cfr. ibid., p. 10); "Hebraei vero hominem in principio nec mortalem manifeste nec inmortalem factum esse fatentur, sed in medio utriusque naturae" (cfr. ibid., p. 11). 
insisten en la caracterización de la naturaleza humana como existente in medio de dos mundos cualitativamente diferentes. Y la misma interpretación del hombre, pero bajo la variante de la idea de medietas, aparece en Máximo el Confesor, ${ }^{15}$ en Juan Escoto Erígena ${ }^{17}$ y en Honorius Augustoduniensis. ${ }^{18}$

En la tradición latina ${ }^{19}$ la idea de horizonte aparece, primero, de modo predominante, más ligada al anima que al hombre. Esta interpretación es ratificada por la traducción del Liber de causis, donde el anima es colocada como un horizonte entre la eternidad inferior y el tiempo. ${ }^{20}$ Esta idea del horizonte ligada al anima asume la forma del horizonte en el sentido de medium ${ }^{21}$ entre dos órdenes. ${ }^{22}$ Pero en la tradición latina la condición de medium es aplicada tambien al hombre, ${ }^{23}$ como es el caso en Guillermo de Conches ${ }^{24}$ y Pedro Lombardo, ${ }^{25}$ para quienes el hombre aparece in medio entre dos naturalezas.

En Tomás de Aquino la tradición latina encuentra una de las formulaciones más interesantes de la idea de microcosmos aplicada al hombre. El microcosmos de Tomás sintetiza sentidos atribuidos por la tradición griega y la latina, retoma la idea del homo como horizon, confinium, medium entre dos naturalezas y atribuye al hombre todas estas características como equivalentes de la noción de microcosmos en quien omnia congregantur. ${ }^{26} \mathrm{La}$ idea fundamental implícita en el concepto de homo microcosmos transmitida por Tomás de Aquino es que el hombre

15 "Ideoque velut medius est intellectualis et sensibilis substantiae, copulatus secundum corpus quidem et corporales virtutes irrationalibus animalibus et inanimatis, secundum rationale vero incorporeis substantiis, ut dictum est prius" (cfr. Némésius d'Emése. De natura hominis. Traduction de Burgundio de Pise. Edition critique avec une introduction sur l'anthropologie de Némésius par G. Verbeke et J.R. Moncho, Leyden, 1975, p. 6); "Quasi igitur medius terminus irrationalis et rationalis naturae homo constitutus..." (cfr. ibid., p. 9); "Hebraei autem hominem a principio neque mortalem concesse neque immortalem generatum esse aiunt, sed in medio termino alterutrius naturae..." (cfr. ibid., p. 10).

cfr. Ambigua, I, XXXVII, en Migne, PG, XCI, col. 1305 A 8-B 5 y B 13-C 2.

cfr. Periphyseon, Lib. II, en la ed. de Y. B. Sheldon-Williams, Dublin, 1972, p. 18 y 28.

cfr. Clavis Physicae, a cura di P. Lucentini, Roma, 1974, p. 49.

9 Para una presentación general del concepto de horizonte en la tradición latina v. N. Hinske, ut supra, nota 10. Del artículo de Hinske resulta que la tradición latina identifica el alma con el horizonte.

"Esse vero quod est post aeternitatem et supra tempus est anima, quoniam est in horizonte aeternitatis inferius et supra tempus" (Liber de causis, II, 22, ed. por A. Pattin, en Tijdschrift voor Filosofie, 28, 1966, p. 50).

Para el significado del horizonte como medium aplicado al anima, v. Hinske, ut supra, nota 10. "Humanus animus quasi in medio collocatus quadam conditionis suae excellentia" (cfr. Alcherius de Clairvaux, Liber de spiritu et anima, en Migne, PL, col. 814).

Para la idea del hombre como medium en San Agustín v. M. Kurdzialek, ut supra, nota 10, p, 70, nota 133; la misma idea en Bemardo Silvestre ibid., p. 69.

24 "Exigit autem ut quemadmodum sunt quedam rationalia sine sensu ut angeli, quedam sensibilia sine ratione ut bruta animalia, sit quoddam medium quod et rationale sit et sensibile ut homo" (cfr. Glosae super Platonem, de. E. Jeauneau, Paris, 1965, p. 223).

25 "Et sicut factus est homo propter Deum, id est, ut ei serviret, ita mundus factus est propter hominem, scilicet ut ei serviret. Positus est ergo homo in medio, ut et ei serviretur et ipse serviret" (In Sent., II, 8).

"[...] in homine quodammodo omnia congregantur. Homo enim est quasi horizon et confinium spiritualis et corporalis naturae, ut quasi medium inter utrasque, utrasque bonitates participet et corporales et spirituales; unde et 'omnis creaturae nomine homo intelligitur', Marc., ult., 15 ubi dicitur 'Praedicate Evangelium omni creaturae'..." (cfr. Super Libro Tertio Sententiarum, Prologus). 
constituye una suerte de confluencia y de síntesis completa de todos los niveles de realidad (omnia congregantur) que, colocados cada uno en su lugar y orden, están bien discriminados en el macrocosmos. Pero al mismo tiempo, porque el hombre como microcosmos congrega a la totalidad del mundo macrocosmos, es horizonte, confin y medio a partir del cual se pueden discriminar y distinguir dos naturalezas. En Tomás, sin embargo, el hecho de que la idea del hombre como microcosmos arrastre consigo la idea del hombre como límite, confín o medium entre dos naturalezas presenta una multivocidad que no implica equivocidad. Pues porque el hombre es microcosmos, es decir, porque es un punto de reunión y síntesis de todos los ámbitos de lo real, ello sugiere al mismo tiempo que el hombre constituye el ámbito de la realidad por donde es posible hacer pasar el límite entre la realidad espiritual y material.

En otros términos, en virtud de que a partir de la idea del hombre como microcosmos podemos transitar a las ideas de horizonte, límite, confín y medio pues se trata en todos los casos de conceptos que se requieren entre sí - por ello mismo el microcosmos es un concepto muy eficiente para señalar dos dimensiones del hombre que coexisten simultáneamente en él: por una parte su dimensión propiamente microcósmica como síntesis de todos los niveles de realidad y por la otra su dimensión como medio, es decir como lugar a partir de la cual es posible señalar la separación y la discriminación entre los dos ámbitos de la realidad más diferenciables: la realidad espiritual y la material. De hecho, creo es muy posible que en el tratado De ecclesiastica potestate ${ }^{27}$ Egidio Romano haya utilizado el significado tomista de microcosmos en el sentido de lugar en el que todo lo real confluye ( $=$ microcosmos) y que Dante, en la Monarchia haya aprovechado la multivocidad tomista del microcosmos para utilizarlo en el sentido de lugar a partir del que lo real puede ser diferenciado (= medium y horizonte).

\section{Homo $=$ microcosmos en el tratado De ecclesiastica potestate de Egidio Romano}

Egidio no intenta fundamentar que la Iglesia está por encima de reinos y naciones, sino el modo como la Iglesia está colocada sobre ellos. Para ello recurre a un argumento del tratado De angelica hierarchia del Pseudo Dionisio según el cual la estructura metafísica de la realidad presenta una reducción de lo inferior a lo mediante intermediarios, ${ }^{28}$ i.e. gradualmente, no immediate, sino per media. ${ }^{29} \mathrm{Si}$ en el proceso de reducción no hubiera mediación, no habría orden en el universo, y ello se opondría a la relación ordenada de poderes que, según el Evangelio, a Deo

27 Cito en lo sucesivo página de la edición de R. Scholz, Aegidius Romanus. De ecclesiastica potestate, Scientia, Aalen, 1961

28 "Possumus enim ex ordine universi hoc liquido declarare, quod super gentes et regna sit ecclesia constituta. Nam secundum Dionysium in De Angelica Ierarchia lex divinitatis est infima in suprema per media reducere. Hoc ergo requirit ordo universi, ut infima in suprema per media reducantur" (p. 12) Subrayado nuestro.

${ }^{29}$ "Si enim eque immediate infima reducerentur in suprema, sicut et media, non esset universum recte ordinatum..." (p. 12). 
ordinata sunt. ${ }^{30} \mathrm{Si}$ cada una de las espadas - que según el Evangelio existen dentro de la Iglesia - no estuviera subordinada a la outra, ${ }^{31}$ esos poderes y autoridades no estarían sujetos a un orden. Por ello la espada temporal debe estar ordenada a la espiritual del mismo modo como lo inferior se ordena a lo superior, ${ }^{32}$ es decir, mediante intermediarios.

Egidio recoge una objeción a este modo de relación de poderes, que tiende a crear una autonomía de lo temporal. Afirma que aunque reyes y príncipes están subordinados a la Iglesia, lo están solamente en relación con lo espiritual, no con lo temporal. Según la objeción, puesto que las cosas temporales tienen origen temporal, la subordinación de la espada temporal a la Iglesia no tiene lugar en relación con las cosas específicamente temporales - que quedanian dentro de la estricta jurisdicción de la espada temporal - sino que se limita a las cosas espirituales que, como tales, son de competencia exclusiva de la Iglesia. ${ }^{33}$ Egidio responde que si así fuera, no podria haber reducción de las cosas inferiores a las superiores pasando por las intermedias y que, en consecuencia, no habria orden entre ellas. Por ello es necesario que el Papa tenga dominio sobre el orden temporal. ${ }^{34}$ Más aún, el dominio que la Iglesia ejerce de iure en el orden espiritual habla de una excelencia de la Iglesia como poder espiritual que implica su dominio en el orden temporal. ${ }^{35}$ Por ello, en virtud de ese dominio, la Iglesia puede llegar a amonestar a los príncipes seculares. ${ }^{36}$

Sin embargo, el hecho de que el Papa goce de dominium in temporalibus parece contradecir el principio de economía: ¿cómo justificar la existencia del poder temporal si -a través de intermediarios - ese poder temporal es totalmente reducido al espiritual? Si el Papa tiene un dominio absoluto, que se extiende a todo el orden temporal, la sola existencia de la espada espiritual parece bastar para actuar directamente sobre el orden temporal. ${ }^{37}$ Egidio responde que aunque el poder

30 "[...] quod est inconveniens dicere et potissime in istis potestatibus et auctoritatibus, quod patet ex sententia apostoli ad Romanos XIII qui, cum prius dixisset, quod non est potestas nisi a Deo, postea immediate subiungit: Que autem sunt a Deo, ordinata sunt" (p. 12).

${ }^{31}$ "Si ergo duo sunt gladii, unus spiritualis et alter temporalis, ut potest patere ex sententia evangelii: Ecce gladii duo hic, ubi statim subiungit dominus: Satis est, quia hii duo gladil sufficiunt in ecclesia, oportet hos duos gladios, has duas auctoritates et potestates a Deo esse; quia, ut dictum est, non est potestas nisi a Deo" (p. $12 \mathrm{~s}$.$) .$

"Gladius ergo temporalis tamquam inferior reducendus est per spiritualem tamquam per superiorem, et unus ordinandus est sub alio tamquam inferior sub superiori" (p. 13).

"Sed dicere aliquis, quod reges et principes debent esse subiecti spiritualiter, non temporaliter, ut secundum hoc sit intelligendum quod dictum est, quod reges et principes spiritualiter, non temporaliter subsint ecclesie. Sed temporalia ipsa, diceret aliquis, ecclesia recognoscit ex dominio temporali..." (p. 13).

${ }^{34}$ "Nam si solum spiritualiter reges et principes subessent ecclesie, non esset gladius sub gladio, non essent temporalia sub spiritualibus, non esset ordo in potestatibus, non reducerentur infima in suprema per media. Si igitur hec ordinata sunt, oportet gladium temporalem sub spirituali, oportet sub vicario Christi regna existere; et de iure, licet aliqui de facto contrarie agant, oportet Christi vicarum super ipsis temporalibus habere dominium" (p. 13).

"Nam de iure simpliciter dominans spiritualiter per quandam excellentiam eciam super temporalibus habet dominium" (p. 13).

36 "Potest autem ecclesia animadvertere in seculares principes, cum temporalis gladius sit sub spintuali gladio constitutus" (p. 13). "[...] quia cum potestas spiritualis extendat se ad omnia et iudicet omnia, non solum animas, sed eciam corpora et res exteriores, videtur, quod unus solus gladius sufficiat" (p. 112). 
espiritual se extienda a toda la realidad, debe dedicarse a actuar sobre lo mejor de ella. De allí la necesidad de un segundo poder que se ocupe de lo menos noble de toda esa realidad, de modo que el poder espiritual pueda ocuparse con más dedicación de las cosas divinas ${ }^{38}$ La justificación de la existencia del poder temporal pasa, pues, por la diferencia entre el ejercicio de la potestas simpliciter y specialiter. Aunque specialiter, de modo particular, cada una de esas potestates se ocupa de ámbitos diferentes de la realidad, de modo absoluto, esto es simpliciter, la potestas spiritualis alcanza a toda la realidad. Un solo poder sería suficiente solo si lo que es hecho por uno es hecho de modo eficiente. Pero si en la Iglesia existiera solo la espada espiritual, ésta debería ocuparse de cosas materiales y ello redundaría en perjuicio de la eficiencia de la espada espiritual en el orden espiritual. ${ }^{30}$ Mientras en casos normales la espada material se ocupa de cosas materiales, solamente si la situación excepcional lo exige, la espada espiritual puede ocuparse de las cosas materiales. ${ }^{40}$ Pero no por existir la espada espiritual - superior y de más alcance que la material - ésta deja de existir o de cumplir sus funciones. ${ }^{41} \mathrm{La}$ función de la espada material caduca solo en caso de excepción: si casus immineat.

Egidio insiste en que a pesar de la existencia en la Iglesia de la espada espiritual, sin embargo no es superflua la existencia en ella de la espada material, pero descarta que esa existencia se justifique en el hecho de que la espada espiritual pueda con la material algo que no podría sin ella, ${ }^{43}$ pues en ese caso habría algún poder en las cosas inferiores que no habría en las superiores ${ }^{44}$ afirmación desmentida por el hecho de que a la Iglesia fueron confiados al mismo tiempo ambos poderes. ${ }^{45}$ Esta aclaración anticipa que la preferencia de Egidio en favor de

38 "[...] sed ut potestas spiritualis magis vacare posset rebus divinis... bene se habuit statuere secundum gladium, qui preesset corporalibus rebus. Sed quando due potestates ita se habent, quod una se extendit ad omnia, videlicet ad magis nobilia et ad minus nobilia, sed ut liberius vacare possit circa magis nobilia, instituitur secunda potestas que specialiter vacet circa minus nobilia, oportet tunc potestatem institutam ad vacandum circa minus nobilia esse sub potestate altera, et oportet eam esse institutam per alteram et habere quod habet ex commissione alterius potestatis. Sic est in proposito. Nam potestas spiritualis extendit se ad spiritualia tamquam ad magis nobilia, et ad corporalia tamquam minus nobilia... [ergo] bonum fuit instituere secundam potestatem que specialiter preesset rebus corporalibus, ad hoc, quod spiritualis potestas circa spiritualia liberius vacare posset. Potestas ergo spiritualis est potestas generalis et extensa, cum non solum ad spiritualia, sed ad corporalia se extendat..." (p. 113).

39 "[...] verum est, si potest fieri per illud unum eque bene et eque decenter; sed si non esset nisi unus gladius in ecclesia, videlicet spiritualis, ea quae agenda essent in gubernacione hominum non fierent eque bene, quia exinde spiritualis gladius multa obmitteret que agenda essent circa spiritualia, ex eo quod oporteret ipsum intendere circa materialia" (p. 115).

40 "Non dicimus autem, quod si casus immineat, quod non possit spiritualis gladius circa materialia intendere... Quod ergo institutus est secundus gladius, non est propter impotenciam spiritualis gladii, sed ex bona ordinacione et ex decencia" (p. 115).

41 " $[. .$.$] nec tamen propter potestatem spiritualem, que est generalis, superfluit potestas terrena, que$ est contracta et particularis" (p. 116/7).

42 "Quod cum duo gladii sint in ecclesia...gladius inferior non superfluit propter superiorem, sed hii duo gladii decorant et omant ecclesiam militantem" (p. 129).

43 "[...] quoniam aliquid potest superior cum potestate inferiori...quod non potest sine ill[a]..." (p. 129).

44 "quia aliqua potestas potest esse in inferioribus que non est in superioribus nec a superioribus" (p. 135)

45 " $[. .$.$] quia utrumque gladium habet ecclesia et utramque potestatem, sibique simul terreni et celes-$ tis iura imperii sunt commissa, extra quam non est.salus..." (p. 135). 
la existencia de dos espadas no tiene que ver con la presencia en la espada espiritual de algún minus que haría necesaria la existencia de un segundo poder complementario. De allí que su argumentación se oriente a demostrar, no la necesidad esencial de la existencia de un segundo poder, sino la conveniencia de que ese segundo poder coactúe con la espada espiritual en favor de una mejor disposición del gobiemo del mundo. La espada material no es superflua porque en casos normales favorece esa mejor disposición.

La situación presentada crea un espacio para ambas espadas. Pero esa situación de ningún modo es presentada por Egidio como esencialmente diferente a la situación en la que todo el poder sería ejercido solamente por la espada espiritual. Dos son las proposiciones claves en la construcción de su argumentación: (a) todo lo que la espada espiritual puede con la material lo puede tambien sin ella; (b) la existencia de la espada material como potestas no superflua se justifica porque ella puede hacer en la realidad, de otro modo, lo que en casos excepcionales la espada espiritual puede hacer sobre la misma realidad directamente y simpliciter. De estas dos proposiciones, solo la proposición (a) presenta una situación esencialmente inalterable, pues ella se refiere a la esencia de los poderes. Pero mientras ella presenta una situación esencial, la proposición (b) presenta una situación referida al modo de ejercicio de los poderes, acerca de cuya esencia e inalterabilidad - no acerca del modo de ejercitarlos - se expide la proposición (a). Así, la proposición (b) es inalterable en todo lo que ella reitera la proposición (a) - o en todo aquello de la proposición (a) que está contenido en ella - pero es alterable en todo lo que ella agrega a la proposición (a), i.e. en cuanto al modo como los poderes referidos por la proposición (a) son ejercidos en este mundo. De allí que la situación presentada por la proposición (b) es más conveniente solo en cuanto al modo de ejercicio del poder, pues contribuye a la mejor disposición y orden de la realidad. La pregunta se impone: ¿cuándo puede ser alterada esa situación (b), de tal manera que la espada espiritual, ordenada por conveniencia a lo espiritual, se ocupe tambien de lo material? Egidio responde con rapidez: en caso de excepción. ${ }^{46} \mathrm{El}$ Papa, en cuanto gobierna la Iglesia siguiendo la ley común, actúa uniformemente frente a cada uno de los miembros de esa Iglesia, ${ }^{47}$ conserva a cada uno en su estado, no impide el oficio de ninguno ${ }^{48}$ y no se entromete en los asuntos temporales que corresponden a los poderes temporales. ${ }^{49}$ Pero el Papa tiene un dominio universal sobre las cosas temporales, ${ }^{50} \mathrm{y}$ aunque según la ley común - que respeta en situaciones normales - no se entromete en lo temporal, puede hacerlo en caso

46 "Nam quia spiritualis gladius est tam excellens et tam excellentia sunt sibi commissa, ut liberius possit eis vacare, adiunctus est sibi secundus gladius, ex cuius adiunccione in nullo diminuta est eius iurisdictio et plenitudo potestatis ipsius sed ad quandam decenciam hoc est factum, ut qui ordinatur ad magna, nisi casus immineat, non se intromittat per se ipsum et immediate de parvis" ( $p$. 145 s.). El destacado es mío.

47 "Sicut ergo censendum est de Deo, prout secundum legem communem gubernat totum mundum, sic eciam censendum est de vicario Dei, prout secundum communem legem totam ecclesiam gubernat" (p. 152).

48 "[...] summus pontifex... secundum legem communem gubernat ecclesiam et ad omnia uniformiter se habet, quia omnia in suo statu conservat... nullum in suo officio impedit..." (p. 155). "Secundum... legem communem non intromittet se Papa de temporalibus..." (p. 156). "[...] ipse tamen secundum communem legem mundum gubernat..." (p. 156). 
de que suceda en ellas algo excepcional, que exige su intervención directa in temporalibus. ${ }^{51}$ Esta intervención implicará - como sucede si Dios interviene más allá de la ley común - actuar más allá del normal curso normal de los acontecimientos. ${ }^{52}$

Dejemos de lado momentáneamente el caso de excepción, en el que el Papa interviene directamente in temporalibus,${ }^{53} \mathrm{y}$ volvamos a la tipificación del poder del Papa en casos de normalidad. En estos casos es más conveniente que la potestas papal, que en sí es absoluta y tiene un dominio universal sobre las cosas temporales, sea ejercida de modo indirecto, mediatizada por la autoridad temporal. Dicho de otro modo: aunque en casos normales es el poder temporal el que es ejercido directamente o primariamente sobre las cosas temporales, el poder del Papa, porque es absoluto y principal, ${ }^{54}$ sigue presente en ese ejercicio, pero indirectamente.

Como ejemplo de ese poder papal absoluto ejercido en casos normales indirectamente in temporalibus, Egidio recurre a la analogía macrocosmos/ microcosmos. Pero en lugar de buscar en el macrocosmos lo que sucede en el microcosmos, procede a la inversa, y presenta lo que sucede en el hombre microcosmos como prueba analógica de lo que sucede en el macrocosmos, entendiendo por macrocosmos no el mundo en su totalidad sino el ámbito en el que se verifica el gobierno de todos los hombres. ${ }^{55}$

El hombre, como microcosmos, dirige sus actos con un poder doble: uno corporal, el sentido, que tiende directamente a las cosas temporales, otro espiritual, la inteligencia, que tiende de modo reflejo a esas mismas cosas; por ello dice Aristóteles que la inteligencia sabe que existe la carne solo por vía refleja. ${ }^{56} \mathrm{De}$ inmediato Egidio saca su conclusión que traslada la estructura cognoscitiva del hombre al microcosmos universal de gobierno para casos normales: del mismo modo como lo hace el sentido corporal, tambien el poder temporal actúa directamente sobre el mundo material, y del mismo modo como lo hace la inteligencia, tambien el poder espiritual actúa indirectamente en lo temporal, por más que, como quedó dicho, casualiter, es decir, en caso de excepción, el poder espiritual debe ejercer su poder directamente en lo temporal. ${ }^{57}$

51 "[...] non intromittet se Papa de temporalibus; sed secundum specialem legem [intromittet se]..."; "... nisi aliud speciale in talibus [rebus temporalibus] occurrat..." (p. 156).

${ }^{52}$ "[...] Deus preter solitum cursum et preter communem legem velle aliqua operari" (p. 161).

53 "[... [ non intromittet se Papa de temporalibus; sed secundum specialem legem [intromittet se]..."; "... nisi aliud speciale in talibus [rebus temporalibus] occurrat..." (p. 156).

54 ibid., p. 163.

55 "Que omnia scientibus naturalia optime placere debent; nam quilibet homo est microcosmos, idest minor mundus: nam ea que sunt in universali mundo relucent in homine quasi in quodam minon mundo, et illa que videmus in gubernacione omnium hominum, in uno et eodem homine conspicere possumus" (ibid., p. 166).

56

"in quolibet homine est duplex genus potencie per quod dirigitur in suis actibus: unum quidem genus est quasi corporale et materiale, ut sensus; aliud quidem genus est quasi spirituale et abstractum, ut intellectum. Sensus quidem tamquam potencia corporalis et materialis directe tendit in hec corporalia, intellectus vero nonnisi per reflexionem in hec particularia et camalia et sensibilia tendit. Ideo de potencia intellectiva dicitur in tercio De Anima, quod cum sit reflexa, carnis esse cognoscit" (ibid., p. 167).

57 "Sicut ergo in gubernacione tocius humani generis sunt due potestates, per quas regitur vel regi debet totum humanum genus, una corporalis et materialis, ut potestas terrena, alia spiritualis et sa- 


\section{Dante: la distinción de los poderes mediante la interpretación del microcosmos como medium}

En el Libro III de la Monarchia Dante se propone demostrar, ostensive, que la autoridad del Emperador depende de Dios, pero inmediate, es decir, sin ningún intermediario. Para ello construye su argumentación en tres momentos bien ligados entre sí. ${ }^{58}$ El primero es un momento cosmológico, que considera el mundo como dividido en naturaleza comuptible e incorruptible. El segundo momento es antropológico. En este segundo momento Dante coloca y tipifica al hombre como un ente limítrofe u orizon, es decir punto medio - medium - entre la naturaleza corruptible e incorruptible. ${ }^{59}$ El tercer momento es ético político, y en él Dante demuestra su tesis de la independencia de poderes.

A partir del momento cosmológico y pasando por el antropológico, Dante hace deslizar toda su argumentación a través de lo que llama el sector comuptible de lo real en cada uno de esos dos primeros momentos: entia corruptibilia en el primer momento, y homo corruptibilis en el antropológico. Es claro que el momento antropológico cumple una función mediatizante e intermediaria entre el momento cosmológico y el momento ético-político, el tercer y último momento de la argumentación. Este momento antropológico, pues, permite el tránsito teórico desde las tesis cosmológicas hacia las tesis ético-politicas en las que Dante introduce, en primer lugar, la tesis ética de los dos fines del hombre - el de este mundo y el de la vida futura ${ }^{60}$ - independientes entre sí, y luego, de inmediato, la tesis propiamente política de la independencia de la autoridad imperial respecto de la autoridad papal.

Reconstruyendo ahora la misma argumentación, pero de modo inverso, tenemos, en primer lugar, que la tesis política que afirma la independencia de poderes depende de la tesis ética de la independencia de fines, en segundo lugar que esta

cerdoialis, ut potestas ecclesiastica, sic... in quolibet homine est duplex genus potencie per quod dirigitur in suis actibus: unum quidem genus est quasi corporale et materiale, ut sensus; aliud quidem genus est quasi spirituale et abstractum, ut intellectum. Sensus quidem tamquam potencia corporalis et materialis directe tendit in hec corporalia, intellectus vero nonnisi per reflexionem in hec particularia et camalia et sensibilia tendit. Ideo de potencia intellectiva dicitur in tercio De Anima, quod cum sit reflexa, carnis esse cognoscit...Potestati itaque terrene commisa sunt ista materialia et temporalia quantum ad particularem execucionem et immediatam operacionem directe; sed potestati spirituali quantum ad principale dominium, quantum ad superiorem et primariam potestatem, omnia temporalia et universus orbis de iure, etsi non de facto, quia non omnes obediunt evangelio, est sibi commissus. Sed quantum ad particularem execucionem et quantum ad immediatam operacionem, generaliter et regulariter non decet summo pontifici, quod se de temporalibus intromittat, cum ipse specialiter circa spiritualia debeat esse intentus; tamen, ut diximus, casualiter, idest in casu et propter aliquod speciale, debet iurisdiccionem in temporalibus exercere" (ibid., p. 167).

Una presentación detallada del problema en mi trabajo "Dalla cosmologia alla politica (Osservazioni sulla 'Monarchia' di Dante, III, xv", en Revista da Faculdade de Ciências Sociais e Humanas (As relações de poder no pensamento político da baixa idade média-Homenagem a Joao Morais Barbosa), I (1994), p. 285/302. Una versión española del mismo trabajo en "Contexto, consecuencias y fuentes de la doctrina dantesca 'homo est medium'", en Patristica et Mediaevalia XIII (1992), p. $3 / 21$. 
tesis ética depende de la tesis antropológica de la coexistencia en el hombre de dos naturalezas diferentes y, en tercer lugar, que esta tesis antropológica depende, a su vez, de la tesis cosmológica referida a la constitución del cosmos entendido como un único todo, pero dividido en una naturaleza corruptible y otra incorruptible.

La articulación de toda esta argumentación en tres momentos revela, por una parte, que en la colocación del hombre "inter omnia entia" y en la afirmación de que /homo/ "solus in entibus tenet medium" descansa un evidente interés de Dante por articular todo su discurso tomando como punto de partida una estructura teórica que implique a todo lo real, es decir, a omnia entia; se trata de una estructura abarcadora de toda la realidad que actúa como terminus a quo de toda la argumentación, de modo que el primer sciendum de esa argumentación es el mundo como totalidad. Pero por otra parte de esa articulación surge al mismo tiempo que Dante ha procurado vincular, de modo directo e inmediato, su tesis ético-política, es decir el terminus ad quem de la argumentación, con el momento antropológico, es decir con el momento en que utiliza el motivo del hombre como medium u horizonte entre dos mundos.

Esta estrecha vinculación y dependencia de la política respecto de la antropología muestra que la conclusión política central del tratado es derivada inmediatamente de la interpretación del hombre como medium y orizon, es decir de la consideración del hombre como miembro de un universo integrado por dos naturalezas diversas y al mismo tiempo como ente que participa de cada una de ellas. Por ello el hombre es al mismo tiempo corruptible e incorruptible. La importancia que en la construcción de esta argumentación asume el momento antropológico invita a penetrar en él para examinar la idea que constituye el núcleo teórico sobre la base del cual Dante construye ese momento; ese núcleo teórico está constituído por la doctrina del hombre como medium y orizon entre dos mundos, es decir, como punto de encuentro, pero en especial y al mismo tiempo como límite de separación entre el mundo corruptible y el incorruptible.

Si consideramos ahora de modo concreto la expresión dantesca "omnia entia" referida al momento cosmológico - que es la expresión a partir de la que se desencadena toda la argumentación del capítulo XV del Libro III - percibimos que esos "omnia entia" no son considerados como región unitaria u homogénea. Se trata, al contrario, de un ámbito signado por la fractura, al que Dante ha recurrido y ha presentado de ese modo fracturado porque como lo ha señalado Kantorowicz, su discurso político está anclado solamente en un sector del mundo en el que la teoria política dantesca encuentra sus raíces. ${ }^{61}$ Precisamente, para vincular la dimensión política del hombre con uno de esos dos sectores del mundo y transformar esa dimensión en independiente respecto del otro sector, Dante ha apelado a uno de los significados implícitos en el microcosmos, el de medium y orizon. ${ }^{62}$

${ }^{61}$ E. Kantorowicz, The King's Two Bodies. A Study in Medieaeval Political Theology, Princeton, 1957, p. 457.

Q2 "homo solus in entibus tenet medium...; propter quod recte a philosophis assimilatur horizonti, qui est medium" (cfr. M,III,xv, 272, 9-10) 
El significado de microcosmos tomado por Dante es, pues; doble: por una parte está orientado a sugerir y mostrar de modo tácito que el hombre es un mundo menor porque sintetiza a ambos mundos y reúne la naturaleza de toda la realidad material y espiritual; al mismo tiempo - y ésto es lo que aquí interesa - a subrayar de modo explícito un significado implícito en el primero, i.e. que el hombre es el lugar de la realidad por donde pasa el límite entre el mundo natural y el mundo espiritual. En ese sentido, porque es un lugar de confluencia, pero al mismo tiempo de separación entre dos mundos, el hombre es llamado, además de horizonte, medium y confinis.

Es posible que tambien Dante, como ya lo había hecho Egidio, haya tomado la idea de microcosmos de la formulación de Tomás de Aquino $0^{63}$ de alguna similar en la que están presentes ambos sentidos de microcosmos, el de reunión de todo lo real y el de horizonte entre el mundo material y espiritual. Pero al mismo tiempo que ha asumido la idea del hombre como el lugar de lo real en el que omnia congregantur,'sin embargo, a efectos de conducir la argumentación hacia el ámbito de lo corruptible, Dante ha orientado toda su argumentación de modo tal que el peso de su interpretación del microcosmos esté todo en la significación del microcosmos como orizon y medium. 